\title{
National Societies Complement EPS Initiatives
}

Professor Jean Muller, President of the Swiss Physical Society, reports that a solidarity initiative called "Action Est" in favour of national societies in east and central Europe resulted in a remarkable response. Some SFR 10000.- has been collected from members in the form of contributions to help the region's members meet their annual EPS membership fees during the difficult transition period to market economies. A second transfer to EPS will probably be made at the end of the year since contributions continue to be sent to the fund's bank account in Switzerland. As a measure of the generosity, one notes that Switzerland represents $3 \%$ of the national society membership in EPS so an equivalent response from other similar societies would imply a total of over 300 kSFR. The Swiss society's policy will be to continue to channel E\&CE initiatives through EPS, the only important exception being an ETH Zurich-based scheme to collect and distribute in Romania books, journals and equipment.

\section{Other Responses}

There have been other responses to the appeal by Maurice Jacob, the EPS President, at Council in Athens earlier in the year for special temporary support from richer societies to help some E\&CE societies pay their full fees. Formal approval by the Board of the Swedish Physical Society to contribute onethird of the Estonian Physical Society's membership fee is imminent and the Governing Board of the Finnish Physical Society has already agreed to pay another third. The two societies are also offering some less official help to Estonia, mostly following a request from Tartu University for help to plan a technical faculty, but without any commitment to approach funding agencies on behalf of the university. Professor Gunnar Tibell, the Swedish society's President, feels providing advice is best handled within the context of the evaluation of science in Estonia that is being coordinated by Dr. Lars Gidefeldt of the Swedish Science Research Council. The final report to be published next month gives detailed recommendations for specific sub-fields (five are in physics) on a project-by-project basis. The evaluation, resembling those carried out routinely in Sweden, is the first to be performed by the Swedish SRC elsewhere and follows a request by the Estonian Academy of Science which realises that the amount of research it performs must be reduced. A similar evaluation of Latvian physics by the Danish Natural Sciences Research Council will be completed in December. Both Dr. Gidefeldt and Professor Jen-Urik Andersen, the Chairman of the Danish council, remarked on the wide variation of the quality of research in any given field, with some groups clearly being at a very high level. There is no commitment at present to followup with project support, although Professor Andersen hoped that the Swedish evaluation will be taken into consideration by European Community programmes covering the Baltic states. Finally, the Finnish and Estonian societies are exchanging delegates to annual meetings as a way to keep informed of each other's activities.

\section{The Fee Question}

As the fee question remains a concern, both now and in the medium term within the context of a restructuring of EPS, Norbert $\mathrm{Kroo}$, the Vice-President, was asked by the Executive Committee to discuss ways to handle the problem with the societies concerned. His hope, expressed in an interview published this month in Czechoslovakia, is that society fees to EPS will eventually be considered, at least in part, by most countries in the framework of international scientific relations. Czechoslovak physicists are represented in EPS by the Physics Section of the Union of Czechoslovak Mathematicians and Physicists. The total Union membership is 7000; that of the combined Czech and Slovak physics sections some 1500. The Union's international obligations have up to now been met by the Czechoslovak Academy of Sciences but a new law voted in two months ago by Parliament which comes into force on 1 January 1993 sees the reconstitution of the academy as a purely Czech academy (the Slovak republic has always had its own academy as the federal structure was asymmetric). The new law is not detailed so the status of former commitments has to be sorted out. This means exploring possibilities for fee payment in the context of an evolving funding situation - a pattern that generally repeats itself throughout E\&CE.

\section{Parallel Initiatives}

There are some important national initiatives to help less fortunate countries which run in parallel to the normal EPS activities funded in part by national membership fees. The German Physical Society (GPS) for obvious historical reasons leads the way. The society has maintained a policy of direct support for the eastern part of Germany from the very beginning of the reunification process. Hence, it continues to send free copies of Physikalishe Blätter (the GPS bulletin) to institutes although the number involved is now down to 300 . The GPS's main activity is to administer grants from the W.E. Heraeus Foundation aimed at improving contacts within Germany and between E\&CE and Germany, especially between the eastern part with its former partners. For example, support is given to students attending EPS, GPS and IUPAP conferences and to some invited speakers at GPS meetings [1]. A new initiative involving three 1992 summer schools for primarily east German students is supported by a $50 \mathrm{kDM}$ Heraeus grant. The GPS also advises universities and governments on restructuring and maintains long-established bilateral agreements with societies in E\&CE to promote exchanges, the new feature being to expand them to other counties, notably Czechoslovakia.

The Institute of Physics (IoP) in the UK does not have quite the same degree of historical involvement but remains nonetheless an important contributor to east-west initia- tives owing to its size and importance. Alun Jones, the loP Chief-Executive, writes to say that a three-year agreement was signed with the Polish Physical Society in January to arrange financial support for conference participation and to facilitate direct contacts at the laboratory level. The loP also ensures that Poland receives at least one copy of every journal published by IoP Publishing (IOPP) together with initial discounts for new journals. Similar arrangements are being discussed with Hungary and Czechoslovakia. Some 15 Academy of Sciences libraries in the former Soviet Union have been given free subscriptions, a practice that may cease unless individuals assure IOPP that the journals are reaching their correct destinations. Readers in the FSU who feel they can justify direct support in the form of free journals should contact the IOPP [2].

Professor Renato Ricci, the President of the Italian Physical Society (IPS), indicated at Council in Athens that his society would get in touch with national societies in the Balkans to see what could be done about the problem of meeting the payment of fees. Since then the IPS has been seeking to profit from the coordinated activities that take place within the context of the Alpe Adria, a wellestablished regional socio-economic association linking institutions in Slovenia, Croatia, Austria, and Italy. Meanwhile, the society has sent missing volumes and new subscriptions of mainly IPS-published journals to libraries in Romania and a similar initiative is envisaged for Albania.

The main effort of The Netherlands' Physical Society targeted specifically at E\&CE involves cooperation with the Physica Foundation (derived from profits for publishing activities) and the government funding agency FOM in handling in 1992/3 some $50 \mathrm{kHFL}$ for promoting contacts that could develop into joint projects with Dutch physicists [3].This action follows support worth $60 \mathrm{kHFL}$ which was distributed to young physicists to attend the 1990 EPS-8 General Conference in Amsterdam. The Dutch society assists E.W.A. Lingeman, the Secretary of the EPS East-West Coordination Committee. This committee, which includes American Physical Society participation following the EPSAPS "summit" in Budapest in May, next meets in October in Amsterdam.

\section{CONTACTS FOR INFORMATION}

[1] Travel grants to Germany: W. Heinicke, Hauptgeschäftsführer, DPG, Haupstr. 5, W5340 Bad Honnef.

[2] IOPP journals for the FSU: IOPP, Techno House, Bristol BS1 6NX, UK.

[3] Travel grants to The Netherland's: A.M. Hoogenboom, Secretary, NNV, Julianalaan 74, NL-3722 GS Bilthoven.

\section{ANNOUNCEMENT}

\section{3-18 Sept. 1993 Ascona, Switzerland}

Magnetoelectric Interaction Phenomena in Crystals: 2nd Int. Conf.

O. Hirth, MEIPIC, Secr. de Chimie appliquée, Univ. de Genève

30, quai Ernest-Ansermet,

$\mathrm{CH}-1211$ Geneva 4

+41 (22) $7026408 / 3296102$

MEIPIC@sc2a.unige.ch

PP: 13 Sep 93 / limited to 100 /

SFR 400.- incl. proc. / ETH Zurich 